\title{
Investigation of the Relationship between Three- and One-Dimensional Infiltration Using a Mini Disc Infiltrometer ${ }^{\dagger}$
}

\author{
George Kargas, Paraskevi Londra * and Konstantinos Anastasiou \\ Department of Natural Resources Management and Agricultural Engineering, Agricultural University of \\ Athens, 75 Iera Odos Street, 11855 Athens, Greece; kargas@aua.gr (G.K.); akwstas1@gmail.com (K.A.) \\ * Correspondence: v.londra@aua.gr; Tel.: +030-210-5294-069 \\ + Presented at the 3rd EWaS International Conference on "Insights on the Water-Energy-Food Nexus", \\ Lefkada Island, Greece, 27-30 June 2018.
}

Published: 31 July 2018

\begin{abstract}
Disc infiltrometer experiments were conducted in the laboratory on two disturbed soils, a loam and a silty clay loam soil, in order to investigate the relationship between three- and onedimensional infiltration using the proposed equation of Smettem et al. A mini disc infiltrometer of a radius of $45 \mathrm{~mm}$ with suction ranged from $-5 \mathrm{~mm}$ to $-70 \mathrm{~mm}$ was used. Three- and onedimensional infiltration tests were performed on repacked cores by applying pressure heads -70 , -40 and $-10 \mathrm{~mm}$ for loam soil, and -30 and $-10 \mathrm{~mm}$ for silty clay loam soil. Analysis of the results showed that the difference between the three- and one-dimensional infiltration is linear with time confirming the equation of Smettem et al. [1]. Also, this difference is used to calculate the value of an additional infiltration parameter.
\end{abstract}

Keywords: infiltration; soil sorptivity; mini disc infiltrometer

\section{Introduction}

Knowledge of both soil water infiltration characteristics, saturated hydraulic conductivity and soil sorptivity, of the upper soil layers is essential for the modeling of field infiltration process for hydrological applications and agricultural water management.

Tension disc infiltrometers, among other experimental apparatus used in situ for determining these two infiltration characteristics, has been extensively used in last decades [1-5]. Tension disc infiltrometers allow measurements of infiltration with a constant and small negative pressure head, ho, at the soil surface and has been extensively used to measure the near-saturated hydraulic conductivity, $K_{0}$, and sorptivity $S_{0}[1-5]$. Disc infiltrometers have the advantage that are portable and use small volumes of water making them suitable for spatial variability studies [6-8].

Various methodologies have been proposed to determine $K_{0}$ and $S_{0}$ from three-dimensional infiltration data from circular source at soil surface using tension disc infiltrometer. Among these, some are based on steady-state flow data and others on transient flow data [2,4,9-14].

In case of steady-state flow from circular source with constant negative pressure head at soil surface, the analytical solution of Wooding [15], is used. Wooding's equation is applied by assuming that the soil is homogenous and isotropic and the initial water content is uniform. Hydraulic conductivity near saturation can be determined by steady-state infiltration experiments either using multiple-discs with the same pressure head imposed at the surface, or by single-disc infiltration experiments with multiple pressure heads [16]. Wooding's approach uses a two-parametric model for determining the hydraulic conductivity [17]. However, it is quite difficult to obtain reliable values 
of sorptivity using infiltration data by disc infiltrometer since there is a difficult to determine the required short time where gravity ignored [12].

Due to uncertainties about the time at which a steady-state infiltration regime is attained, together with the fact that useful information is lost by ignoring the transient stage, several researchers use a transient three-dimensional infiltration equation for disc infiltrometers [18]. Although, several expressions for transient infiltration [3,4,12], have in common the following twoterm cumulative infiltration equation analogous to Philip [19],

$$
I_{3 D}=C_{1} \sqrt{t}+C_{2} t,
$$

where I is the cumulative infiltration $(\mathrm{L})$ and the subscript 3D refers to three-dimensional infiltration process. The coefficients $C_{1}$ (L T-0.5) and $C_{2}$ (L T-1) differ among the expressions used [18].

Haverkamp et al. [4], related $C_{1}$ and $C_{2}$ to $S_{0}$ and $K_{0}$ for short and medium times as follows:

$$
\begin{gathered}
C_{1}=S_{0}, \\
C_{2}=\frac{2-\beta}{3} K_{0}+\frac{\gamma S_{0}^{2}}{r\left(\theta_{0}-\theta_{n}\right)},
\end{gathered}
$$

where the subscript 0 refers to values on the supply boundary where the pressure head is ho $(\mathrm{L}), n$ refers to the initial conditions, $r$ is the disc radius (L), $\beta$ is a shape factor lying between 0 and 1 , and $\gamma$ is a proportionality coefficient. The coefficient $\gamma$ was originally set equal to $\sqrt{0.3}$ by [1], and later was revised to be $0.6<\gamma<0.8$ by [4]. Consequently, the Equation (1) takes the following form:

$$
I_{3 D}=S_{0} \sqrt{t}+\frac{2-\beta}{3} K_{0} t+\frac{\gamma S_{0}^{2}}{r\left(\theta_{0}-\theta_{n}\right)} t
$$

The first term of the right-hand side in Equation (4) represents vertical capillary flow and dominates the infiltration during the initial stage. The second term represents gravity-driven vertical flow and the third term represents lateral capillary flow.

Smettem et al. [1], showed that the additional term accounting for the side effects due the axisymetric flow geometry is linear in time:

$$
I_{3 D}-I_{1 D}=\frac{\gamma S_{0}^{2}}{r\left(\theta_{0}-\theta_{n}\right)} t
$$

where the subscript 1D refers to one-dimensional infiltration process.

In order to apply Equation (5) an estimation of $C_{1}=S_{0}$ and $\gamma$ is required.

However, Vandervaere et al. [5], had reported that the calculation of $C_{1}$ and $C_{2}$ parameters by direct nonlinear fitting of Equation (1) on experimental data can provide fitted values for $C_{1}$ and $C_{2}$, even if these values have no physical meaning, e.g., negative $C_{2}$ value. So, negative $K_{0}$ is a physical impossibility indicating a problem with the data set. To overcome this problem, various linear fitting techniques of Equation (1) have been proposed to detect possible inadequacy of Equation (1), as well as scattering of data points.

Smiles and Knight [20], proposed linearizing of Equation (1) by dividing both sides by $\sqrt{t}$, giving the equation:

$$
\frac{I_{3 D}}{\sqrt{t}}=C_{1}+C_{2} \sqrt{t}
$$

and then plotting $I_{3 D} / \sqrt{t}$ as a function of $\sqrt{t}$. Thus, it is easy to determine $C_{1}=S_{0}$ as the intercept and $C_{2}$ as the slope of the fitted line on experimental data. Also, $S_{0}$ could be estimated from cumulative one-dimensional infiltration data versus square root of time, at short times, where this relationship is linear with slope $S_{0}$. 
The main purpose of this study is to investigate the difference between three- and onedimensional infiltration on two disturbed soils, a loam and a silty clay loam soil, using a mini disc infiltrometer and to compare this difference with the proposed equation of Smettem et al. [1].

\section{Materials and Methods}

A mini disc infiltrometer [21], with a radius of $22.5 \mathrm{~mm}$ was used to perform three-dimensional infiltration experiments on repacked soils into a cylinder of $300 \mathrm{~mm}$ diameter and $300 \mathrm{~mm}$ length and the disc was placed in the center of the box to allow fully unconfined three-dimensional flow. On the other hand, one-dimensional infiltration experiments were performed on repacked soils into a cylinder of $45 \mathrm{~mm}$ diameter and $500 \mathrm{~mm}$ length and the disc was placed on the top surface of the soils.

The soils examined were a Loam (L) and a Silty Clay Loam (SiCL). The soil texture and the bulk density, $Q_{\varphi}$, of soils are presented in Table 1 . The disturbed soil samples used had been air dried before the beginning of the experiments and consequently the initial soil water content was very low $\left(\theta_{\mathrm{n}}=0.04 \mathrm{~cm}^{3} \mathrm{~cm}^{-3}\right.$ for both soils). The pressure heads applied, during the three- and one-dimensional infiltration tests, were $-70,-40$ and $-10 \mathrm{~mm}$ for the $\mathrm{L}$ soil, and -30 and $-10 \mathrm{~mm}$ for the SiCL soil. After cessation of each infiltration experiment, soil samples were obtained to determination soil water content.

Table 1. Soil particle size distribution and bulk density, Q $\varphi$, of the soils examined.

\begin{tabular}{ccccc}
\hline Soil Type & Clay (\%) & Silt (\%) & Sand (\%) & $\mathbf{Q}_{\varphi}\left(\mathbf{g}_{\mathbf{c}} \mathbf{c m}^{-3}\right)$ \\
\hline L & 20.0 & 38 & 42.0 & 1.17 \\
SiCL & 36.5 & 52 & 11.5 & 1.23 \\
\hline
\end{tabular}

The duration of the experiments ranged from 600 to $900 \mathrm{~s}$. The sorptivity $S_{0}$ value for each pressure head ho was obtained by plotting one-dimensional infiltration data $I_{1 D}$ as a function of $\sqrt{t}$, for short times up to $60 \mathrm{~s}$ where the $I_{1 D}(\sqrt{t})$ relationship is linear.

\section{Results and Discussion}

In Figure 1, three- and one-dimensional infiltration relationships are depicted for $\mathrm{L}$ and SiCL soils for each pressure head used.

\section{Loam}

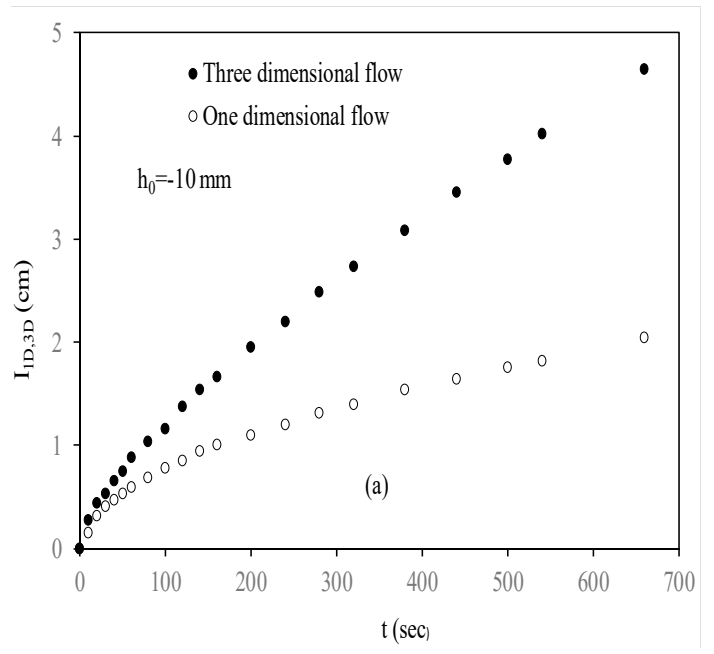

Silty Clay Loam

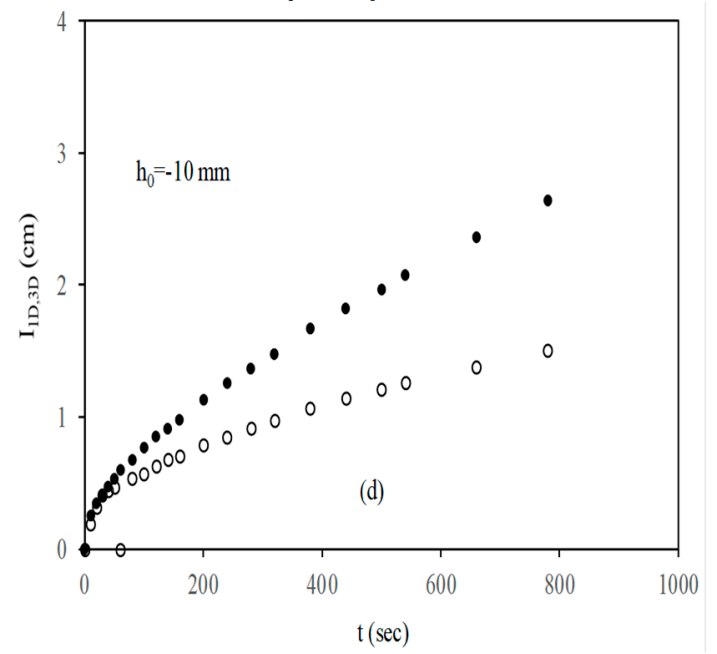



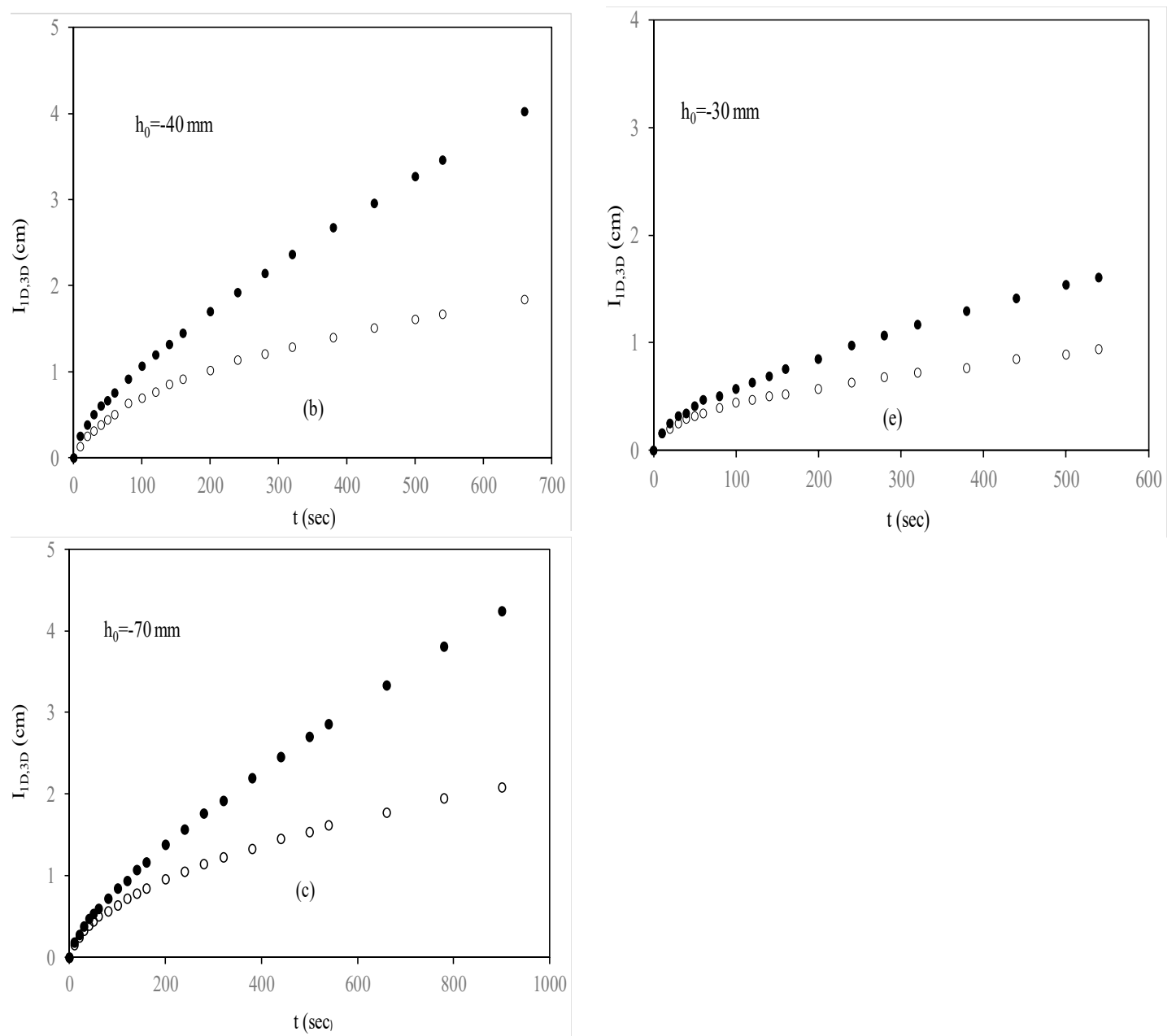

Figure 1. Representation of three- and one-dimensional experimental infiltration data with time,

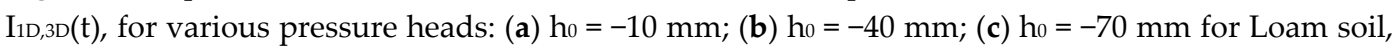
and (d) ho $=-10 \mathrm{~mm} ;(\mathbf{e}) \mathrm{h}_{0}=-30 \mathrm{~mm}$ for Silty Clay Loam soil.

At short times $(t \rightarrow 0)$, the sorptivity $S_{0}$ can be calculated by the equation $I_{3 D}=I_{1 D}=S_{0} \sqrt{t}$. However, Smettem [22], and Minasny and McBratney [23], showed that the classical approach to calculate sorptivity from a disk infiltrometer experiment (three-dimensional infiltration flow) may give erroneous result (overestimated). For this reason, $S_{0}$ value, for each pressure head, was obtained from the slope of the linear relationship of the one-dimensional infiltration data versus square root of time, $I_{1 D}(\sqrt{t})$, (data not shown) for short times where the effect of the gravity is negligible (Table 2).

Table 2. Parameters of one-dimensional infiltration experiment for loam (L) and silty clay loam (SiCL) soil and the coefficient of determination $\mathrm{R}^{2}$ between the experimental infiltration data $I_{1 D}(\sqrt{t})$ and fitted curve for $S_{0}$ estimation.

\begin{tabular}{ccccc}
\hline Soil Type & Pressure Head, $\mathbf{h}_{\mathbf{0}}(\mathbf{m m})$ & Water Content, $\boldsymbol{\theta}_{\mathbf{0}}\left(\mathbf{c m}^{3} \mathbf{c m}^{-3}\right)$ & Soil Sorptivity, $\mathbf{S}_{\mathbf{0}}\left(\mathbf{c m ~ s}^{-0.5}\right)$ & $\mathbf{R}^{2}$ \\
\hline \multirow{2}{*}{$\mathrm{L}$} & -10 & 0.385 & 0.072 & 0.970 \\
& -40 & 0.369 & 0.063 & 0.958 \\
& -70 & 0.362 & 0.058 & 0.986 \\
\hline \multirow{2}{*}{ SiCL } & -10 & 0.464 & 0.061 & 0.990 \\
& -30 & 0.446 & 0.046 & 0.990 \\
\hline
\end{tabular}

The one-dimensional infiltration data were used in contrast to the three-dimensional infiltration data, since the corresponding time where the $I_{3 D}(\sqrt{t})$ function is linear, is much shorter and therefore is uncertain in estimation of $S_{0}[4]$. The choice of the appropriate time interval for calculating $S_{0}$ in the 
one-dimensional infiltration experiments, where the soils used are fine-textured and disturbed, is relatively easy since no sand layer is needed to be used on the surface of each porous medium to ensure hydraulic contact between the infiltrometer and the soil. The presence of this layer can be affect on the first stages of infiltration making difficult the estimation of the appropriate time interval for calculating $S_{0}[5,24]$. The value of $S_{0}$ at each pressure head can also be calculated by linearization methodologies of the Equation (1) using one- or three-dimensional infiltration data $[5,20,22]$. The applied methodology, in this study, for estimation of $S_{0}$ value for each pressure head compared with the aforementioned linearization method gave similar results. Perroux and White [25], after conducting disc infiltrometer experiments, showed that the time for estimating $S_{0}$ depends on the soil type and ranged from 6 to $2450 \mathrm{~s}$ with an average value of $60 \mathrm{~s}$.

In Figure 2, the fitted curves of the linear relationship $\frac{I}{\sqrt{t}}=C_{1}+C_{2} \sqrt{t}$ on the three- and onedimensional infiltration data using pressure head $\mathrm{h}_{0}=-10 \mathrm{~mm}$, for the Loam soil, are presented. Similar results obtained using the other pressure heads for both soils (data not shown).

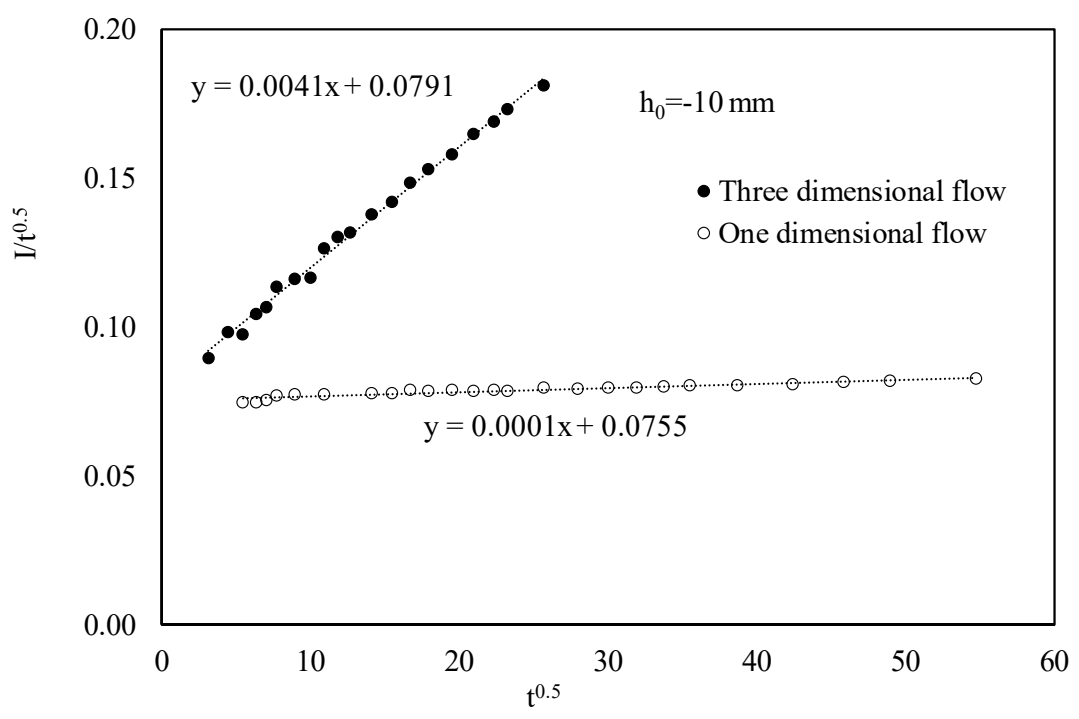

Figure 2. Linear representation of three- and one-dimensional experimental infiltration data and fitted linear lines for pressure head $\mathrm{h}_{0}=-10 \mathrm{~mm}$, for Loam soil.

As shown in Figure 2, both fitting functions (i.e., on three- and one-dimensional infiltration data) have almost the same intercept value $C_{1}=S_{0}$ [13]. The intercept values for all pressure heads tested in the two soils were very close to $S_{0}$ values obtained from the slope of the linear relationship of the onedimentional infiltration data versus square root of time, $I_{1 D}(\sqrt{t})$, and are presented in Table 2. Vandervaere et al. [13], report that a difference up to $15 \%$ between $\mathrm{S}_{0}$ values obtained from three- and one-dimensional infiltration is acceptable due to possible different soil packing.

In Figure 3, the difference between three- and one-dimensional infiltration ( $\left.\mathrm{I}_{3 \mathrm{D}}-\mathrm{I}_{1 \mathrm{D}}\right)$ as a function of time $t$, for each pressure head tested in the two soils, is presented. As shown the difference I3D-IID is linear in time $\mathrm{t}$ for all cases studied, with a coefficient of determination $\mathrm{R}^{2}>0.99$, as predicted by the Equation (5) of Smettem et al. [1], and independent of gravity. It also appears that the slope of this linear function decreases by reducing the pressure head. This practically means that the reduction of $S_{0}$ is greater than the difference of soil water content $\theta_{0}-\theta_{\mathrm{n}}$. 

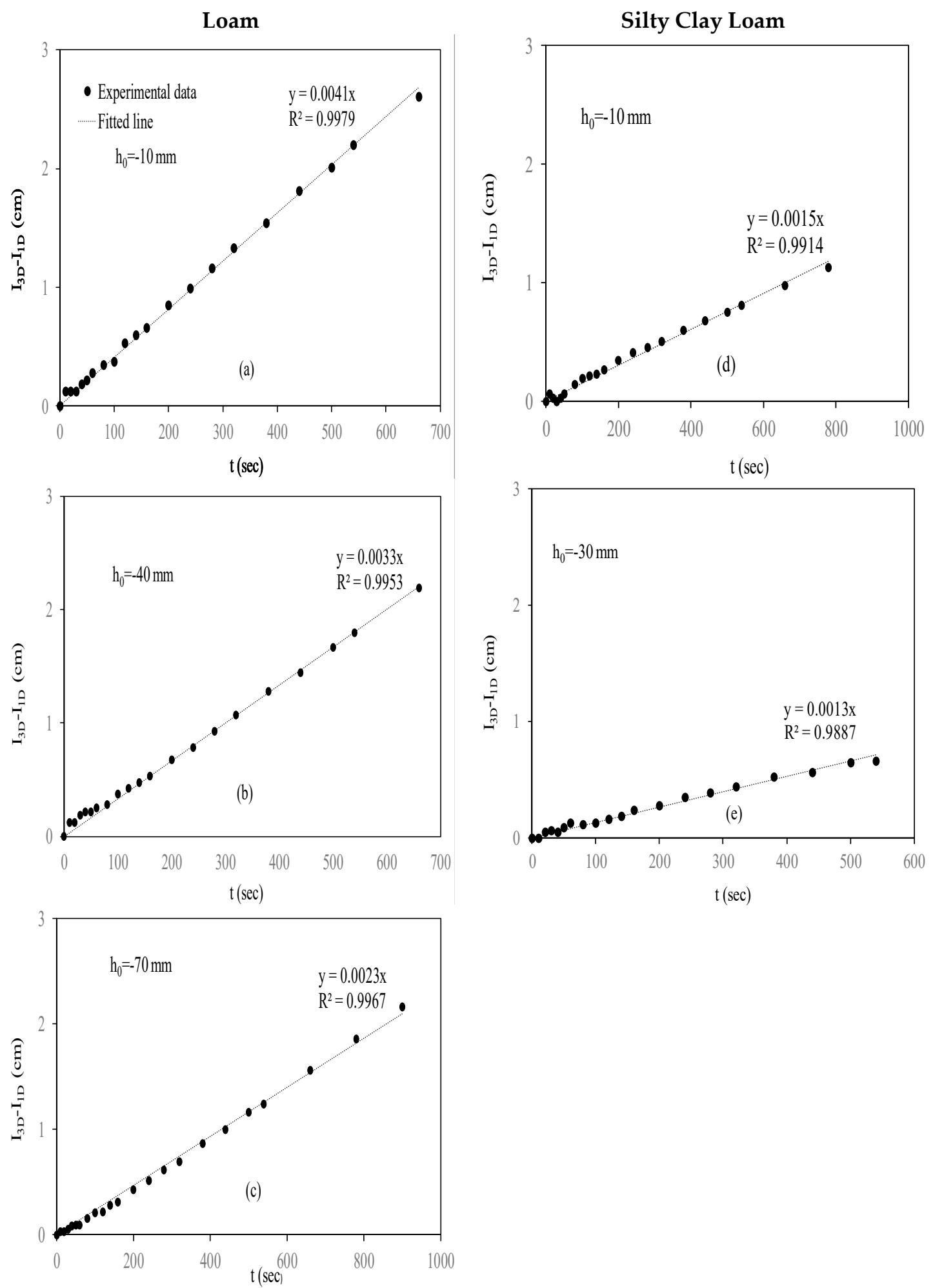

Figure 3. The difference between three- and one-dimensional infiltration flow over time, for pressure heads: (a) ho $=-10 \mathrm{~mm}$; (b) ho $=-40 \mathrm{~mm}$; (c) ho $=-70 \mathrm{~mm}$ for Loam soil, and (d) ho $=-10 \mathrm{~mm}$; (e) $\mathrm{h}_{0}=$ $-30 \mathrm{~mm}$ for Silty Clay Loam soil. The fitted line is from Equation (5).

The comparison between the experimental relationship $\mathrm{I}_{3 \mathrm{D}}-\mathrm{I}_{1 \mathrm{D}}(\mathrm{t})$ and the predicted one by the Equation (5) showed a very good agreement for the proportionality constant $\gamma=\sqrt{0.3}$, for both porous media used. This value of $\gamma$ parameter is given in the model of Smettem et al. [1]. However, the value of $\gamma=0.75$ was suggested by [1], as a result of the comparison between experimental and analytical results in the case of a sandy loam soil. This difference of $\gamma$ values was attributed to the use of sharp wetting front approximation in developing the analytical solution. Haverkamp et al. [4], 
reported that in normal working conditions are reasonably bounded by $0.6-0.8$. In addition, Smettem et al. [22], using a double disc tension infiltrometer in three- and one-dimensional infiltration experiments on a sandy loam soil with pressure head $\mathrm{h}_{0}=-30 \mathrm{~mm}$, found a value of $\gamma=0.726$.

The difference between the experimental value of $\gamma$ of our study and those ones are referred in the works of [4], and [22], can be attributed to various factors such as soil type, initial and boundary conditions, as well as radius of infiltrometer.

\section{Conclusions}

The difference between three- and one-dimensional infiltration flow $\left(\mathrm{I}_{3 \mathrm{D}}-\mathrm{I}_{1 \mathrm{D}}\right)$ is proportional to time as predicted by the equation of Smettem et al. [1]. However, the coefficient $\gamma$ is different from that calculated from other experiments on different soils using different infiltrometers. The calculation of $\gamma$ value, in combination with the value of $S_{0}$, as calculated by various methodologies, can be used to calculate the contribution of gravitational flow during three-dimensional infiltration.

Author Contributions: All authors contributed equivalent.

Acknowledgments: There was no funding source.

Conflicts of Interest: The authors declare no conflict of interest.

\section{References}

1. Smettem, K.R.J.; Parlange, J.-Y.; Ross, P. J.; Haverkamp, R. Three-dimensional analysis of infiltration from the disc infiltrometer: 1. A capillary-based theory. Water Resour. Res. 1994, 30, 2925-2929, doi:10.1029/94WR01787.

2. Smettem, K.R.J.; Clothier, B.E. Measuring unsaturated sorptivity and hydraulic conductivity using multiple disc permeameters. J. Soil Sci. 1989, 40, 563-568, doi:10.1111/j.1365-2389.1989.tb01297.x.

3. Warrick, A.W. Models for disc infiltrometers. Water Resour. Res. 1992, 28, 1319-1327, doi:10.1029/92WR00149.

4. Haverkamp, R.; Ross, P.J.; Smettem, K.R.J.; Parlange, J.-Y. Three dimensional analysis of infiltration from disc infiltrometer 2. Physically-based infiltration equation. Water Resour. Res. 1994, 30, 2931-2935, doi:10.1029/94WR01788.

5. Vandervaere, J.P.; Vauclin, M.; Elrick, D.E. Transient flow from tension infiltrometers: I. The two parameter equation. Soil Sci. Soc. Am. J. 2000, 64, 1263-1272.

6. Smettem, K.R.J. Characterization of water entry into a soil with a contrasting textural class: Spatial variability of infiltration parameters and influence of macroporosity. Soil Sci. 1987, 144, 167-174, doi:10.1097/00010694-198709000-00002.

7. Mohanty, B.P.; Ankeny, M.D.; Horton, R.; Kanwar, R.S. Spatial analysis of hydraulic conductivity measured using disc infiltrometers. Water Resour. Res. 1994, 30, 2489-2498, doi:10.1029/94WR01052.

8. Shouse, P.J.; Mohanty, B.P. Scaling of near-saturated hydraulic conductivity measured using disc infiltrometers. Water Resour. Res. 1998, 34, 1195-1205, doi:10.1029/98WR00318.

9. Clothier, B.E.; White, I. Measurement of sorptivity and soil water diffusivity in the field. Soil Sci. Soc. Am. J. 1981, 45, 241-245.

10. Ankeny, M.D.; Ahmed, M.; Kaspar, T.C.; Horton, R. Simple field method for determining unsaturated hydraulic conductivity. Soil Sci. Soc. Am. J. 1991, 55, 467-470.

11. Reynolds, W.D.; Elrick, E.D. Determination of hydraulic conductivity using a tension infiltrometer. Soil Sci. Soc. Am. J. 1991, 55, 633-639.

12. Zhang, R. Infiltration models for the disc infiltrometer. Soil Sci. Soc. Am. J. 1997, 61, 1597-1603.

13. Vandervaere, J.P.; Vauclin, M.; Elrick, D.E. Transient flow from tension infiltrometers: II. Four Methods to Determine Sorptivity and Conductivity. Soil Sci. Soc. Am. J. 2000, 64, 1272-1284.

14. Latorre, B.; Moret-Fernández, D.; Peña, C. Estimate of soil hydraulic properties from disc infiltrometer three-dimensional infiltration curve: Theoretical analysis and field applicability. Proced. Environ. Sci. 2013, 19, 580-589, doi:10.1016/j.proenv.2013.06.066.

15. Wooding, R.A. Steady infiltration from shallow circular pond. Water Resour. Res. 1968, 4, 1259-1273, doi:10.1029/WR004i006p01259. 
16. Lazarovitch, N.; Ben Gal, A.; Simunek, J.; Shani, U. Uniqueness of soil parameters determined by a combined Wooding inverse approach. Soil Sci. Soc. Am. J. 2007, 71, 860-865.

17. Gardner, W.R. Some steady-state solutions of the unsaturated moisture flow equation with application to evaporation from a water table. Soil Sci. 1958, 85, 228-232, doi:10.1097/00010694-195804000-00006.

18. Vandervaere, J.P. The soil solution phase. In Methods of Soil Analysis: Part 4, Physical Methods; Dane, J.H., Topp, G.C., Eds.; SSSA, Inc.: Madison, WI, USA, 2002; pp. 889-894.

19. Philip, J.R. The theory of infiltration: 4. Sorptivity and algebraic infiltration equations. Soil Sci. 1957, 84, 257-264, doi:10.1097/00010694-195709000-00010.

20. Smiles, D.E.; Knight, J.H. A note on the use of the Philip infiltration equation. Aust. J. Soil Res. 1976, 14, 103108, doi:10.1071/SR9760103.

21. Mini Disc Infiltrometer, User's Manual; Decagon Devices Inc.: Pullman, DC, USA, 2007; 24p.

22. Smettem, K.R.J.; Ross, P. J.; Haverkamp, R.; Parlange, J.-Y. Three-dimensional analysis of infiltration from the disc infiltrometer: 3. Parameter estimation using a double-disk tension infiltrometer. Water Resour. Res. 1995, 10, 2491-2495, doi:10.1029/95WR01722.

23. Minasny, B.; McBratney, A.B. Estimation of sorptivity from disc-permeameter measurements. Geoderma 2000, 95, 305-324, doi:10.1016/S0016-7061(99)00096-8.

24. Vandervaere, J.P.; Peugeot, C.; Vauclin, M.; Angulo-Jaramillo, R.; Lebel, T. Estimating hydraulic conductivity of crusted soils using disc infiltrometers and minitensiometers. J. Hydrol. 1997, 188-189, 203223, doi:10.1016/S0022-1694(96)03160-5.

25. Perroux, K.M.; White, I. Designs for disc permeameters. Soil Sci. Soc. Am. J. 1988, 52, 1205-1215.

(C) 2018 by the authors. Licensee MDPI, Basel, Switzerland. This article is an open access article distributed under the terms and conditions of the Creative Commons Attribution (CC BY) license (http://creativecommons.org/licenses/by/4.0/). 